\title{
Comparative Study of Corrosion Inhibition Efficiency of Naturally Occurring Ecofriendly Varieties of Holy Basil (Tulsi) for Tin in $\mathrm{HNO}_{3}$ Solution
}

\author{
Nutan Kumpawat, Alok Chaturvedi*, Rajesh Kumar Upadhyay \\ Department of Chemistry, Government College, Ajmer (Rajasthan), India \\ Email: ${ }^{*}$ alok_chat.ajm@rediffmail.com
}

Received June 22, 2012; revised July 21, 2012; accepted August 10, 2012

\begin{abstract}
Weight loss technique has been used to study the corrosion inhibition efficiency of tin in $\mathrm{HNO}_{3}$ solution by using the leaves and stem extract of different varieties of Holy Basil viz. Ocimum basilicum $\left(\mathrm{E}_{\mathrm{B}}\right)$, Ocimum cannum $\left(\mathrm{E}_{\mathrm{C}}\right)$ and Ocimum sanctum $\left(\mathrm{E}_{\mathrm{S}}\right)$. The results show that all the varieties under study are good corrosion inhibitors, among which leaves extract of $E_{\mathrm{B}}$ is the most effective. Corrosion inhibition efficiency increases with increasing concentration of inhibitor and it also increases with increasing concentration of $\mathrm{HNO}_{3}$ solution. Inhibition efficiency was found maximum up to $96.19 \%$ for tin with $0.6 \%$ leaves extract.
\end{abstract}

Keywords: Acid Solution; Inhibitors; Tin Metal, Weight Loss; Surface Coverage

\section{Introduction}

Tin and its alloys are found useful for many engineering applications because of their lightness and strength, thermal and electrical conductivity, heat and light reflectivity and hygienic and non-toxic qualities. Tin is a reactive metal according to the electrochemical series $(\mathrm{Eo}=$ $-0.14 \mathrm{~V})$, but it is non reactive in moisture due to the formation of a stable oxide film on its surface. Tin is not attacked by pure water but dissolves in aqueous acids with the liberation of hydrogen gas. Acids like hydrochloric acid, sulphuric acid etc. are used for drilling operation, pickling and descaling. Many workers [1-4] have studied corrosion of tin in $\mathrm{HNO}_{3}$ solution.

Holy basil is a very common plant in India. It is antibacterial, anti-fungal and is used as an air purifier and anti-malarial from ancient times in Indian homes. Powder of its stem and leaves is used as medicine in balancing blood glucose management, to maintain a healthy digestive system, to encourage the efficient use of oxygen, to enhance the efficacy of many therapeutic treatments etc.

The importance of the study lies in the fact that natural plant products are non-polluting, ecofriendly, economic, less toxic and easily available than synthetic organic compounds. They are biodegradable and so can be used without any side adverse effects.

The chemical composition of Ocimum sanctum is highly

"Corresponding author. complex, containing many vitamins like $\mathrm{A}$ and $\mathrm{C}$, calcium, zinc, iron, chlorophyll along with many other phytonutrients which are present in the extract of Ocimum sanctum.

The major chemical constituents responsible for physico-chemical action of Ocimum sanctum are volatile oil $(0.1 \%$ to $0.9 \%)$, eugenol $(60 \%-70 \%)$, cavacrol (about $3.0 \%$ ), eugenol methyl ether (20\%) and other minor chemical constituents of Ocimum sanctum are like alkaloids, glycoside, saponin, tannin, maleic acid, ursolic acid, citric acid and tartaric acid.

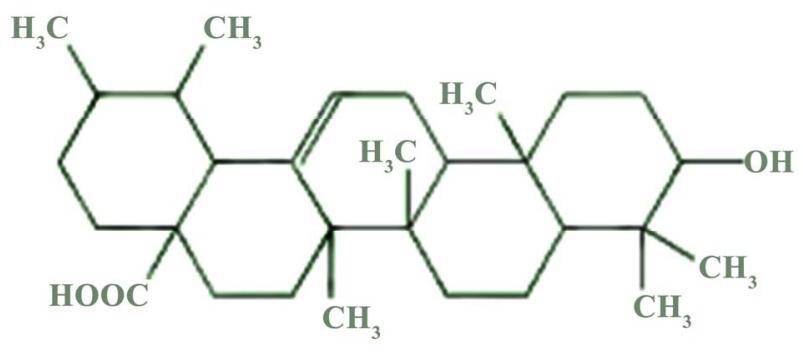

Eugenol

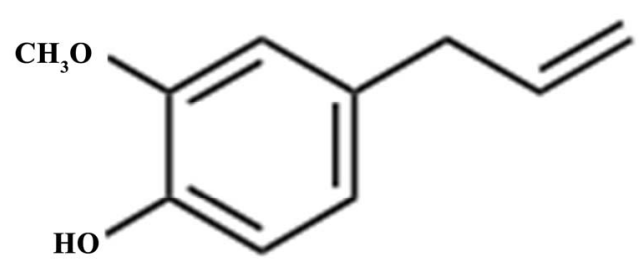

Ursolic Acid 
$\beta$-bisabolene $(13 \%-20 \%)$, methyl chavicol (3\% $19 \%), 1-8$ cineole $(9 \%$ - 33\%), $\alpha$-bisabolene $(4 \%-7 \%)$, $\alpha$-terpineol $(1.7 \%-7 \%)$, campestrol, cholesterol, stigma sterol, $\beta$-sisterol and methyl ester of common fatty acid were the main constituents of the oil which are found in there species.

Generally, the organic compounds containing hetero atoms like nitrogen, oxygen and sulphur etc. have been found to be very effective corrosion inhibitors [5-7]. The efficiency of these compounds depends upon the electron density of hetero atoms. The inhibition efficiency also depends upon the number of adsorption active centers in the molecule, their charge density, molecular size and mode of adsorption and formation of metallic complexes. Atoms such as nitrogen, oxygen and sulfur are capable of forming coordinate covalent bond with metal owing to their free electron pairs. Compounds with $\pi$ bonds like aldehydes, ketones, imines also generally exhibit good inhibitive properties due to interaction of $\pi$ orbital with metal surface.

In addition to the heterogeneous organic compounds like Schiff's bases, Mannic bases etc. which are synthesized in laboratory assist in inhibition, there are also some naturally occurring substances like Ficus virens [8], Delonix regia [9], Ocimum sanctum [10], Caparis deciduas [11], Sanaevieria trifascinata[12], Phylanthus amarus [13], Prosopis julifforar [14], Argemone maxicana [15] etc. have also been evaluated as effective corrosion inhibitors. The present study deals with the study of three varieties of Holy basil i.e. Ocimum basilicum, Ocimum sanctum and Ocimum canum which are most common as corrosion inhibitors of $\mathrm{Al}$ in the most corrosive medium of $\mathrm{HCl}$ solution.

\section{Experimental}

The rectangular specimens of tin of dimensions $2.0 \mathrm{~cm} \times$ $2.0 \mathrm{~cm} \times 0.014 \mathrm{~cm}$ containing a small hole of about 2 $\mathrm{mm}$ diameter near the upper edge were cut from a large sheet of pure tin. The solutions of $\mathrm{HNO}_{3}$ acid were prepared using double distilled water. All chemical used were of analytical reagent grade. Different inhibitor solutions were prepared in absolute ethanol. The extracts of leaves and stem of three varieties were obtained by refluxing the dried leaves and stem in a soxhlet using ethanol as solvent for sufficient time.

Each specimen was suspended with a V-shaped glass hook made of fine capillary and plunged into a beaker containing $50 \mathrm{ml}$ of the test solution $\left(\mathrm{HNO}_{3}\right.$ acid) at room temperature. After sufficient exposure, the test specimens were taken out, washed with running water and dried with hot air dryer. Experiments were repeated in each case and the mean value of the weight loss was calculated. The percentage inhibition efficiency was calculated using the following formula [16].

$$
\eta \%=\frac{\Delta W_{u}-\Delta W_{i}}{\Delta W_{u}} \times 100
$$

where $\Delta W_{u}$ and $\Delta W_{i}$ are the weight loss of the metal in uninhibited acid and in inhibited solution respectively. The corrosion rate (CR) in $\mathrm{mm} / \mathrm{y}$ can be calculated by the following equation [17].

$$
\text { Corrosion rate }(\mathrm{mm} / \mathrm{y})=\frac{\Delta W_{u} \times 87.6}{A \times T \times d}
$$

where, $\Delta W$ is weight loss in $\mathrm{mg}, A$ is area of specimen in $\mathrm{cm}^{2}, T$ is time of exposure in hours and $d$ is density of metal in $\mathrm{g} / \mathrm{cm}^{3}$

The degree of surface coverage $\theta$ by inhibitor can be calculated as

$$
\theta=\frac{\Delta W_{u}-\Delta W_{i}}{\Delta W_{u}}
$$

where $\Delta W_{u}$ and $\Delta W_{i}$ are the weight loss of the metal in uninhibited acid and in inhibited solution, respectively.

\section{Results and Discussion}

Weight loss, percentage inhibition efficiency, corrosion rate and surface coverage in $3.0 \mathrm{M} \mathrm{HNO}_{3}$ solution with different inhibitors of leaves extract are given in Table $\mathbf{1}$. It can be seen from the table that the inhibition efficiency of the inhibitor increases with increasing concentration of inhibitor. The maximum inhibition efficiency (96.19\%) was obtained for Ocimum basilicum $\left(\mathrm{E}_{\mathrm{B}}\right)$ at an inhibitor concentration of $0.6 \%$ in $3.0 \mathrm{M} \mathrm{HNO}_{3}$ solution for leaves extract whereas it was $72.98 \%$ in $3.0 \mathrm{M} \mathrm{HNO}_{3}$ solution with same concentration i.e. $0.6 \%$ for stem extract as shown in Table 2. The results show that there is more inhibition efficiency of Ocimum basilicum than Ocimum canum and Ocimum sanctum in $\mathrm{HNO}_{3}$ solution. The variation of percentage inhibition efficiency $(\eta \%)$ with inhibitor concentration is depicted graphically in Figure $\mathbf{1}$ for leaves extract and in Figure 2 for stem extract in 3.0 $\mathrm{M} \mathrm{HNO}_{3}$ solution. Variation of percentage inhibition efficiency $(\eta \%)$ with the concentration of inhibitor indicate that the inhibition efficiency increases with increasing inhibitor concentration. From Table 1 it is clear that the surface coverage $(\theta)$ increases with increasing concentration of inhibitor.

Adsorption plays an important role in the inhibition of metallic corrosion by organic inhibitors. Many investigators have used the Langmuir adsorption isotherm to study inhibitor characteristics $[18,19]$. Assuming that the inhibitors adsorbed on the metal surface decrease the surface area available for cathodic and anodic reaction to take place. Hoar and Holliday [18] have shown that the Langmuir isotherm,

$$
\log [\theta / 1-\theta]=\log A+\log C-[Q / 2.303 R T]
$$


should give a straight line of unit gradient for the plot of $\log [\theta /(1-\theta)]$ versus $\log C$, where $A$ is a temperature independent constant, $C$ is the bulk concentration of the inhibitor (percentage) and $Q$ is the heat evolved during adsorption.

The corresponding plots, shown in Figures $\mathbf{3}$ and $\mathbf{4}$ for $3.0 \mathrm{M} \mathrm{HNO}_{3}$ for leaves and stem extract are linear but the gradients are not equal to unity as would be expected for

Table 1. Weight loss data $(\Delta W)$ and percentage inhibition efficiency $(\eta \%)$ for Tin in $3.0 \mathrm{M} \mathrm{HNO}_{3}$ solution with given inhibitor additions of leaves extract.

\begin{tabular}{|c|c|c|c|c|c|}
\hline \multicolumn{6}{|c|}{ Area of specimen $=0.056 \mathrm{~cm}^{2}$} \\
\hline \multicolumn{2}{|c|}{ Temperature: $25^{\circ} \mathrm{C} \pm 0.1^{\circ} \mathrm{C}$} & \multirow[b]{2}{*}{ I.E. $(\eta \%)$} & \multirow[b]{2}{*}{ Surface coverage $(\theta)$} & \multicolumn{2}{|c|}{ Exposure time: 7 mins } \\
\hline Inhibition conc. (\%) & $\Delta W(\mathrm{mg})$ & & & Corrosion rate $(\mathrm{mm} / \mathrm{yr})$ & $\log [\theta / 1-\theta]$ \\
\hline Uninhibited & 210 & & & 3153.60 & \\
\hline \multicolumn{6}{|l|}{ Ocimum basilicum $\left(\mathrm{E}_{\mathrm{B}}\right)$} \\
\hline 0.1 & 29 & 86.19 & 0.8619 & 435.50 & 0.7952 \\
\hline 0.2 & 25 & 88.09 & 0.8809 & 375.43 & 0.8690 \\
\hline 0.4 & 17 & 91.09 & 0.9109 & 255.29 & 1.0095 \\
\hline 0.6 & 8 & 96.19 & 0.9619 & 120.14 & 1.4022 \\
\hline \multicolumn{6}{|l|}{ Ocimum саппит $\left(\mathrm{E}_{\mathrm{C}}\right)$} \\
\hline 0.1 & 33 & 84.28 & 0.8428 & 495.57 & 0.7292 \\
\hline 0.2 & 28 & 86.66 & 0.8666 & 420.48 & 0.8126 \\
\hline 0.4 & 23 & 89.04 & 0.8904 & 345.39 & 0.9097 \\
\hline 0.6 & 16 & 92.38 & 0.9238 & 240.27 & 1.0836 \\
\hline \multicolumn{6}{|l|}{ Ocimum sanctum $\left(\mathrm{E}_{\mathrm{S}}\right)$} \\
\hline 0.1 & 36 & 82.85 & 0.8285 & 540.62 & 0.6840 \\
\hline 0.2 & 32 & 84.76 & 0.8476 & 480.55 & 0.7452 \\
\hline 0.4 & 29 & 86.19 & 0.8619 & 435.50 & 0.7952 \\
\hline 0.6 & 21 & 90.00 & 0.9000 & 315.36 & 0.9542 \\
\hline
\end{tabular}

Table 2. Weight loss data $(\Delta W)$ and percentage inhibition efficiency $(\eta \%)$ for Tin in $3.0 \mathrm{~N} \mathrm{HNO}_{3}$ solution with given inhibitor additions of stem extract.

\begin{tabular}{|c|c|c|c|c|c|}
\hline \multicolumn{6}{|c|}{ Area of specimen $=0.056 \mathrm{~cm}^{2}$} \\
\hline \multicolumn{2}{|c|}{ Temperature: $\quad 273 \pm 0.1 \mathrm{~K}$} & \multirow[b]{2}{*}{ I.E. $(\eta \%)$} & \multirow[b]{2}{*}{ Surface coverage $(\theta)$} & \multicolumn{2}{|c|}{ Exposure time: $7 \mathrm{~min}$} \\
\hline Inhibitor conc.(\%) & $\Delta W(\mathrm{mg})$ & & & Corrosion rate $(\mathrm{mm} / \mathrm{yr})$ & $\log [\theta / 1-\theta]$ \\
\hline Uninhibited & 285 & & & 4279.88 & \\
\hline \multicolumn{6}{|l|}{ Ocimum basilicum $\left(\mathrm{E}_{\mathrm{B}}\right)$} \\
\hline 0.1 & 114 & 60.00 & 0.6000 & 1711.95 & 0.1760 \\
\hline 0.2 & 99 & 65.26 & 0.6526 & 1486.69 & 0.2738 \\
\hline 0.4 & 86 & 69.82 & 0.6982 & 1291.47 & 0.3642 \\
\hline 0.6 & 77 & 72.98 & 0.7298 & 1156.32 & 0.4315 \\
\hline \multicolumn{6}{|l|}{ Ocimum саппит $\left(\mathrm{E}_{\mathrm{C}}\right)$} \\
\hline 0.1 & 120 & 57.89 & 0.5789 & 1802.05 & 0.1382 \\
\hline 0.2 & 108 & 62.10 & 0.6210 & 1621.85 & 0.2144 \\
\hline 0.4 & 98 & 65.16 & 0.6516 & 1471.68 & 0.2719 \\
\hline 0.6 & 85 & 70.17 & 0.7017 & 1276.45 & 0.3714 \\
\hline \multicolumn{6}{|l|}{ Ocimum sanctum $\left(\mathrm{E}_{\mathrm{S}}\right)$} \\
\hline 0.1 & 125 & 56.14 & 0.5614 & 1877.14 & 0.1072 \\
\hline 0.2 & 112 & 60.70 & 0.6070 & 1681.92 & 0.1887 \\
\hline 0.4 & 106 & 62.10 & 0.6210 & 1591.81 & 0.2144 \\
\hline 0.6 & 92 & 67.71 & 0.6771 & 1381.57 & 0.3215 \\
\hline
\end{tabular}




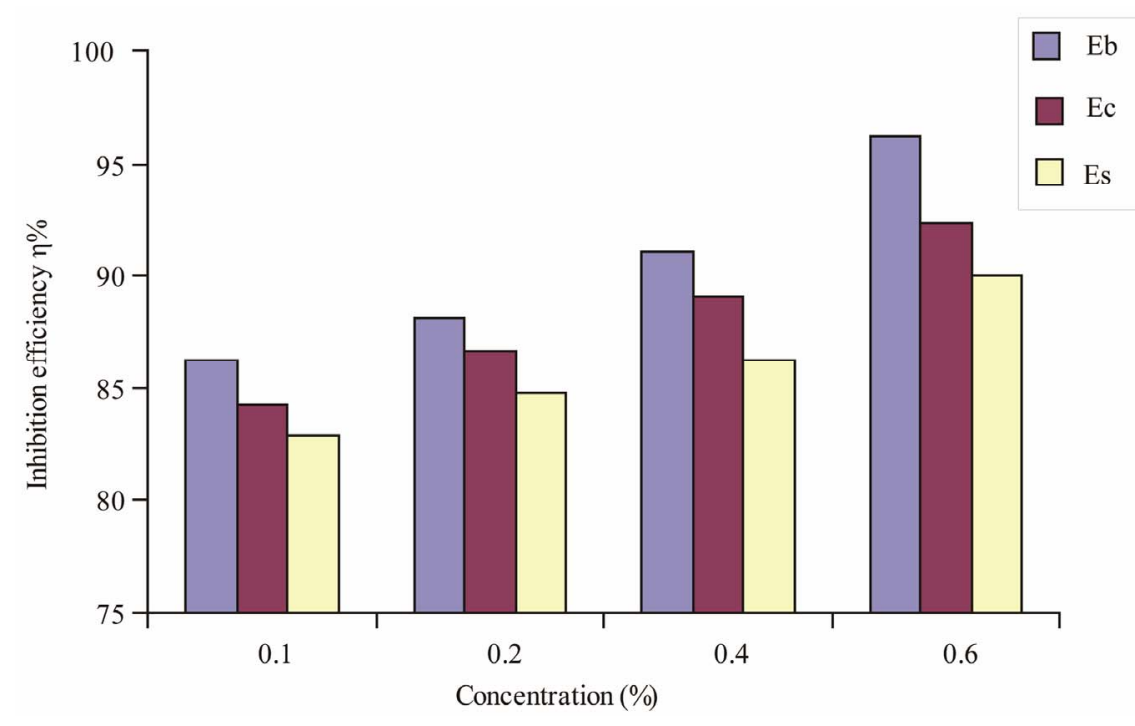

Figure 1. Variation of inhibition efficiency with concentration of leaves extract for Tin in $3.0 \mathrm{M} \mathrm{HNO}_{3}$.

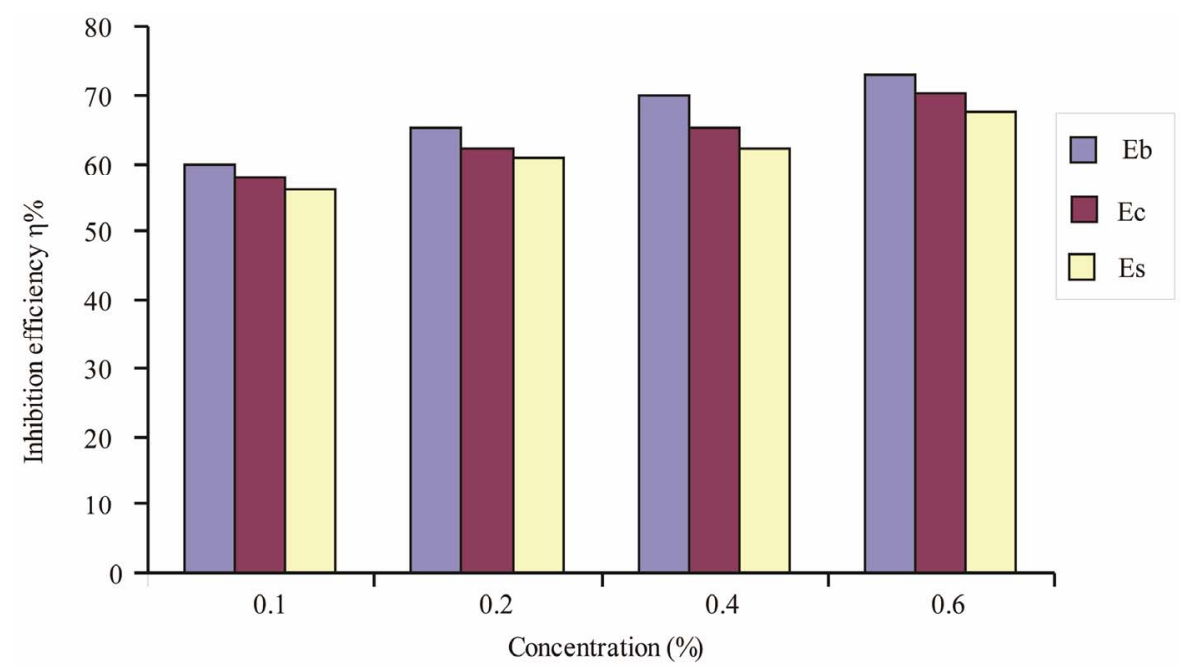

Figure 2. Variation of inhibition efficiency with concentration of stem extract for Tin in $3.0 \mathrm{M} \mathrm{HNO}_{3 .}$

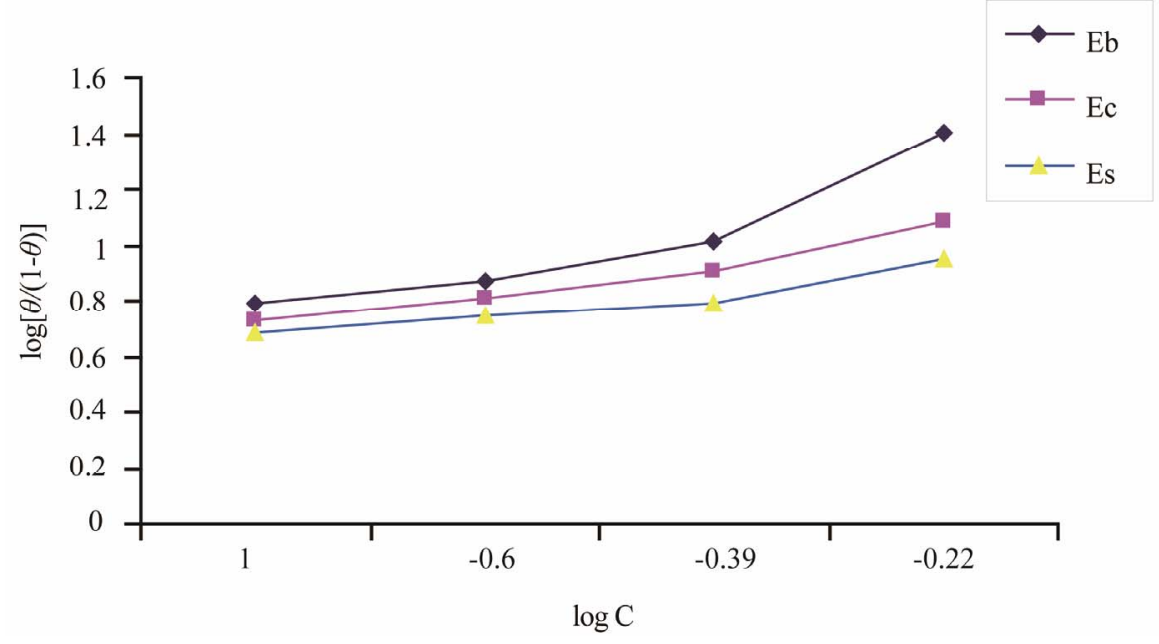

Figure 3. Langmuir adsorption isotherm for Tin in $3.0 \mathrm{M} \mathrm{HNO}_{3}$ with inhibitor concentration for leaves extract. 


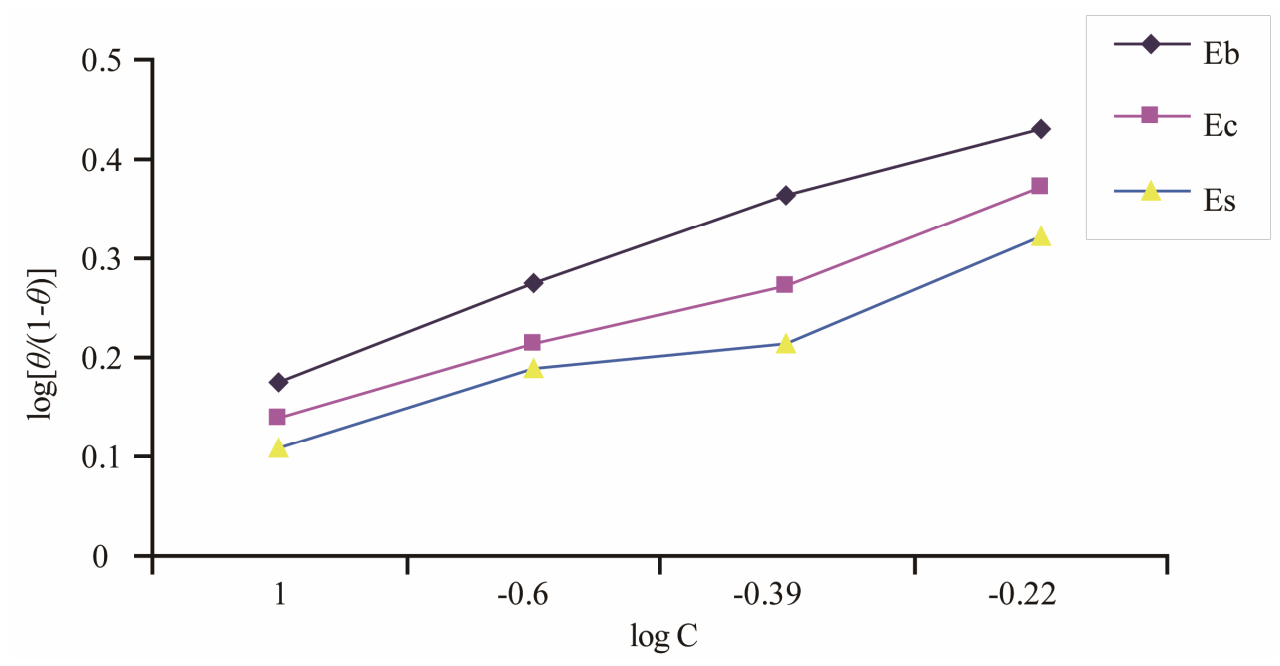

Figure 4. Langmuir adsorption isotherm for Tin in $3.0 \mathrm{M} \mathrm{HNO}_{3}$ with inhibitor concentraction for stem extract.

the ideal Langmuir adsorption isotherm equation. This deviation from unity may be explained on the basis of the interaction among the adsorbed species on the metal surface. It has been postulated in the derivation of the Langmuir isotherm equation that the adsorbed molecules do not interact with one another but this is not true in the case of organic molecule having polar atoms or groups which are adsorbed on the anodic and cathodic sites of the metal surface. Such adsorbed species may interact by mutual repulsion or attraction. Thus, it is also possible for inhibitor molecule those are adsorbed on anodic and cathodic sites to interact with metallic surface as well as with each other.

\section{Conculsions}

A study of three varieties of holy basil viz. Ocimum basilicum $\left(\mathrm{E}_{\mathrm{B}}\right)$, Ocimum cannum $\left(\mathrm{E}_{\mathrm{C}}\right)$ and Ocimum sanctum $\left(\mathrm{E}_{\mathrm{S}}\right.$ ) has shown them to be better corrosion inhibitor for Tin metal in $\mathrm{HNO}_{3}$ solution. $\mathrm{E}_{\mathrm{B}}$ has proved to be an excellent inhibitor for Tin in $\mathrm{HNO}_{3}$ acid due to the presence of methyl eugenol terpenoid (75.69\%).

Weight loss method has shown that inhibition efficiency of holy basil increases with increasing inhibitor concentration over the range $0.1 \%$ to $0.6 \%$ the maximum inhibition efficiency was found up to $96.19 \%$ for tin in 3.0 $\mathrm{M} \mathrm{HNO}_{3}$ acid at a concentration of $0.6 \%$ for leaves extract whereas it was $72.98 \%$ for stem extract with same concentration of acid strength. Thus, it was concluded that leaves extract is a better corrosion inhibitor than stem extract.

\section{Acknowledgements}

One of the authors (Nutan Kumpawat) is grateful to R.G.N. fellowship from U.G.C. govt. of India as J.R.F.

\section{REFERENCES}

[1] A. A. El. Warraky and El. Meleigt, "Electrochemical and Spectroscopic Investigation of Synergestic Effects in Corrosion Inhibition of Al Bronze Part 1-in Pure HCl," Journal of British Corrosion, Vol. 37, No. 4, 2000, pp. 305- 310 .

[2] H. Ashassi-Sorkhabi, B. Shabani, B. Aligholipour and D. Seifzadeh, "The Effect of Some Schiff Bases on the Corrosion of Aluminum in Hydrochloric Acid Solution," Applied Surface Science, Vol. 252, No. 12, 2006, pp. 4039 4047. doi:10.1016/j.apsusc.2005.02.148

[3] G. Berkt, A. Pinarbasi and C. Orgretir, "Benzimidazole-2tione and Benzyoxazole-2-tione Derivatives as Corrosion Inhibitors for Al in $\mathrm{HCl}$ Acid," Anticorrosion, Methods and Materials, Vol. 51, No. 4, 2004, pp. 282-293.

[4] A. H. Ali Ahmed, A. H. Ahmed, T. A. Mohamed and B. H. Mohamed, "Chelates and Corrosion Inhibition of Newly Synthesized Schiff Bases Derived from o-tolidine," Transition Metal Chemistry, Vol. 32, No. 4, 2007, pp. 461-467. doi:10.1007/s11243-007-0184-8

[5] A. Mozaleva APoznyok, I. Mozaleval and A. W. Hassel, "The Voltage-Time Behaviour for Porous Anodizing of Aluminium in a Fluoride-Containing Oxalic Acid Electrolyte," Electrochemistry Communications, Vol. 3, No. 6, 2001, pp. 299-305. doi:10.1016/S1388-2481(01)00157-6

[6] E. E. Ebenso, P. C. Okafor and U. G. Eppe, "Studies on the Inhibition of Al Corrosion by 2-Acetylphenothiazine in Chloroacetic Acids," Anticorrosion, Methods and Materials, Vol. 50, No. 6, 2003, pp. 414-421.

[7] C. Blanc, S. Gastaud and G. Mankowski, "Mechanistic Studies of the Corrosion of 2024 Aluminum Alloy in Nitrate Solutions," Journal of the Electrochemical Society, Vol. 150, No. 8, 2003, pp. B396-B404. doi:10.1149/1.1590327

[8] T. Sethi, A. Chaturvedi, R. K. Upadhyay and S. P. Mathur, "Inhibition Effect of Nitrogen Containing Ligands on Corrosion of Aluminium in Acid Media with and without KCl," Polish Journal of Chemistry, Vol. 82, No. 3, 2008, pp.591-598. 
[9] O. K. Abiola, N. C. Okafor, E. E.Ebenso and N. M. Nwinuka, "Ecofriendly Corrosion Inhibitors: The Inhibitive Action of Delonix Regia Extract for the Corrosion of Aluminium in Acidic Media," Anticorrosion, Methods and Materials, Vol. 54, No. 4, 2007, pp. 219-224.

[10] N. Kumpawat., A. Chaturvedi and R. K. Upadhyay, "A Comparative Study of Corrosion Inhibition Efficiency of Stem And Leaves Extract of Ocimum sanctum (Holy Basil) for Mild Steel in $\mathrm{HCl}$ Solution," Protection of Metals and Physical Chemistry of Surfaces, Vol. 46, No. 2, 2010, pp. 267-270.

[11] P. Arora, S. Kumar, M. K. Sharma and S. P. Mathur, "Corrosion Inhibition of Aluminium by Capparis decideuas in Acidic Media," Journal of Chemistry, Vol. 4, No. 4, 2007, pp. 450-456. doi:10.1155/2007/487820

[12] E. E. Oguzei, "Corrosion Inhibition of Aluminium in Acidic and Alkaline Media by Sansevieria trifasciata Extract," Corrosion Science, Vol. 49, No. 3, 2007, pp. 1527-1539. doi:10.1016/j.corsci.2006.08.009

[13] P. C. Okafor, M. E. Ikpi, I. E. Uwah, E. E. Ebenso, J. Elcpe and S. A. Umoren, "Inhibitory Action of Phyllanthus amarus extract on the Corrosion of Mild Steel in Acid Media," Corrosion Science, Vol. 50, No. 8, 2008, pp. 2310-2317.
[14] N. Kumpawat, A. Chaturvedi and R. K. Upadhyay, "Study on Corrosion Inhibition Efficiency of Stem Alkaloid Extract of Different Varieties of Holy Basil on Aluminium in $\mathrm{HCl}$ Solution," Journal of the Korean Chemical Society, Vol. 56, No. 4, 2012, pp. 1-5.

[15] P. Sharma, R. K. Upadhyay, A. Chaturvedi and R. Parashar, "Study of Corrosion Inhibition Efficiency of Naturally Occurring Argenmone mexicana on $\mathrm{Al}$ in $\mathrm{HCl}$ Solution," Journal of Technical and Research in Chemistry, Vol. 5, No. 1, 2008, pp. 21-27.

[16] J. D. Talati and D. K.Gandhi, "N Heterocylic Compounds as Corrosion Inhibitor for Aluminium Copper Alloy in Hydrochloric Acid," Corrosion Science, Vol. 23, No. 12, 1983, pp. 1315-1332.

[17] D. A. Jones, "Principles and Prevention of Corrosion," 2nd Edition, Prentice-Hall, London, 1996.

[18] T. P. Hoar and R. D. Holliday, "The Inhibition by Quinolines and Thioureas of the Acid Dissolution of Mild Steel," Journal of Applied Chemistry, Vol. 3, No. 11, 1953, pp. 502-513.

[19] J. R. Meakins, “Alkyl Quaternary Ammonium Compound as Inhibitors of the Acid Corrosion of Steel," Journal of Applied Chemistry, Vol. 13, No. 8, 1963, pp. 339-345. 